\title{
РОЛЬ ПОСРЕДНИКА В СПЕЦИАЛЬНОМ ГРАЖДАНСКОМ СПЕЦИАЛЬНОМ СУДЕ 4-ГО СПЕЦИАЛЬНОГО ГРАЖДАНСКОГО СУДА МАСАРÁ-AP, AMAZÔNIA, БРАЗИЛИЯ
}

\section{ОРИГИНАЛЬНАЯ СТАТЬЯ}

NETO, Dalk Dias Salomão¹, SOUSA, Nicole Moreira Faria², DENDASCK, Carla Viana $^{3}$, FECURY, Amanda Alves ${ }^{4}$, OLIVEIRA, Euzébio de ${ }^{5}$, DIAS, Claudio Alberto Gellis de Mattos 6

NETO, Dalk Dias Salomão. Эт аль. Роль посредника в специальном гражданском специальном суде 4-го специального гражданского суда Macapá-AP, Amazônia, Бразилия. Revista Científica Multidisciplinar Núcleo do Conhecimento. Год 06, эд. 05, Vol. 11, стр. 80-92. Май 2021 года. ISSN: 2448-0959, Ссылка доступа: https://www.nucleodoconhecimento.com.br/закон/специальномгражданском, DOI: 10.32749/nucleodoconhecimento.com.br/ru/85947

\section{СВОДКА}

Из-за многочисленных социальных проблем общество стало больше просить справедливости. Существует настоятельная необходимость в новой парадигме, с созданием специальных судебных портфелей, основанных на примирении, в

\footnotetext{
${ }^{1}$ Адвокат, бакалавр права (СЕАР - Центр высшего образования Атара́), специалист по трудовому праву и трудовому процессу в учебном заведении Damásio.

${ }^{2}$ Адвокат, бакалавр права (СЕАР - Центр высшего образования Аmapá), специалист по гражданскому процессуальному праву в учреждении Damásio Educacional.

${ }^{3}$ Богослов, кандидат клинических психоанализов. В течение 15 лет он работал с научной методологией (методом исследования) в научно-производственной ориентации магистрантов и докторантов. Специалист по маркетинговым исследованиям и исследованиям в области здравоохранения, докторант в области коммуникации и семиотики (PUC SP).

${ }^{4}$ Биомедицинская, phD в области тропических болезней, профессор и исследователь медицинского курса кампуса Масара́, Федеральный университет Amapá (UNIFAP), проректор по исследованиям и аспирантуре (PROPESPG) Федерального университета Amapá (UNIFAP).

${ }^{5}$ Биолог, доктор философии в области тропических болезней, профессор и исследователь курса физкультуры, Федеральный университет Pará (UFPA).

${ }^{6}$ Биолог, кандидат теоретических и летных исследований, профессор и исследователь курса химической степени Института базового, технического и технологического образования Amapá (IFAP) и Высшей программы профессионального и технологического образования (PROFEPT IFAP).

$\mathrm{RC}: 85947$

Ссылка доступа: https://www.nucleodoconhecimento.com.br/закон/специальном- 
качестве альтернативного средства урегулирования конфликтов в качестве частичного решения. Специальные суды значительно развились с момента его создания в рамках закона 9.099/95, который оказался чрезвычайно важным для реорганизации правосудия, перед лицом больших требований судебных исков. Цель этой работы заключалась в анализе роли посредника в специальном виртуальном гражданском суде в 4avara специального гражданского суда Macapá AP, Amazônia, Бразилия. Делается вывод о том, что произошла историческая эволюция специальных судей, от их осуществления до принятия закона 9.099/95 до разработки его принципов, таких, как процедурная скорость, неформальность и, все указывает на осуществление более быстрого и эфффективного процесса. PROJUD и TUCUJURIS путем компьютеризации специальных судов, как представляется, имеют важное значение для модернизации этого процесса, делая их более простыми, быстрыми и доступными для всех и, таким образом, следуя мировым технологическим тенденциям. Специальные суды в целом должны стремиться все больше и больше инвестировать в посредников и действия, направленные на примирение, такие, как государственные и национальные недели примирения, поскольку, таким образом, существует большая вероятность того, что дела в судебной системе приобретут большую беглость.

Ключевые слова: Специальный гражданский суд, Примирение, Посредник.

\section{ЗНАКОМСТВО}

Из-за многочисленных социальных проблем общество стало больше просить справедливости, сталкивая с такими проблемами, как большое количество процессуальных требований, задержки в судейском процессах и бюрократия (Sena e Richa, 2011; Guimarães, 2013).

Добавляя эти ситуации с трудностями доступа людей с экономической гипосюсервностью в судебную систему, настоятельно необходимо разработать новую парадигму, которая в качестве частичного решения должна была создать 
специальные суды, основанные на примирении, в качестве альтернативного средства урегулирования конфоликтов (Sérpias, 2015).

Специальные суды в Бразилии, ранее называемые Juizado de Pequenas Causas, смооская американская структура, известная как Small Claims Courts претензиям. Создана в 1934 году в Нью-йорке, с целью пользоваться гражданскими акциями небольшой стоимости. Главной характеристикой этой модели резки является прагматизм, соответствующий американской культуре, то есть конфлликт, который наблюдается, поднимается к более быстрой, незамысловатой и легкой перспективе. Не нужна была фригура адвоката, которого просили в зависимости от сложности ситуации (Porto, 2008).

Эта модель суда появилась в Бразилии, сначала в Rio grande do Sul, в 1982 году, перед функционированием Согласительно-арбитражного совета, созданного с целью урегулирования внесудебного, конфликтов мелких причин, демонстрирующих большой интерес к строительству правосудия (Silva, 2013).

После того, как в 1984 году судебная власть получила известность в национальном сценарии, она в качестве важной вехи стал Законом № 7244, который предусматривает создание и функционирование судов мелких судов, укрепляя и узаконивая успех опыта, полученного в согласительном и арбитражном советах, имея в качестве своей обязанности обеспечение равного правосудия (Silva, 2013).

С этого момента по всей стране начинает появляться несколько специальных судебных разбирательств, регулируемых на государственной службе обычным законом, охватывающим только гражданские причины небольшой экономической ценности, впервые предусмотренные до двадцати (20) минимальных заработных плат. Таким образом, это также позволило наиболее финансово лишенным возможности и правовой гарантии обратиться в судебные органы для достижения мирного урегулирования своих конфликтов (Silva, 2013). 
Федеральная конституция 1988 года продемонстрировала реальную необходимость создания специальных судей и их осуществления на всей территории страны в качестве обязательной меры, поскольку ранее она была факультативной для штатов. CF заверил в своем ст. 98, пункт I, разрешение на осуществление Специальных гражданских судов для согласования, судебного преследования, судьи и выполнения гражданских дел меньшей сложности, а также специальных уголовных судов для согласования, судьи и выполнения уголовных преступлений меньшего наступательного потенциала, через устные и процедур sumaríssimo (без задержек и формальностей) (Sérpias, 2015).

C момента создания дополнительного закона № 123/2006, с целью удовлетворения желаний микро- и малых предпринимателей о конституции и регулировании ME и ЕРP, в целях расширения бизнеса и развития их роста в бразильской экономике. Таким образом, МЭ и ЕНП получили место в национальном сценарии, и из этого общего закона было создано правовое положение о возможности того, что эти виды компаний на государственном уровне, имеющие право на участие в Специальном гражданском суде, появляются в активном полюсе действия (Salomão, 2001). Учитывая возможность доступа в специальный суд, эти компании могут входить в свои акции без присутствия юриста (имеющих потолок стоимости действий до 20 минимальных зарплат), снижая свои расходы. Важно отметить, что дела в специальных судах рассматриваются быстрее, чем в общем суде, что позволяет быстрее вернуть капитал, который до этого был утерян из-за неисполнения должников (Tolentino, 2011).

В 2001 году вскоре после создания закона 9.099/95 (Закон о специальном суде) было создано расширение гражданского суда для обслуживания микропредприятий в Амапа, ввиду того, что они не могли требовать в Центральном специальном суде, который был единственным в эксплуатации в любом штате в то время, имея в качестве координатора магистрата Sueli Pini, в настоящее время председателя Суда Amapá (Serra, 2015). 
Вскоре после создания национального устава ME и EPP был создан дополнительный закон штата № 044/2007, в котором показано, что преимущества закона № 123/06 были приняты правительством Amapá, в марте 2012 года был окончательно создан Специальный суд микропредприятий и малого бизнеса (Serra, 2015).

Суд микропредприятий в Amapá играет соответствующую роль благодаря разработанной работе и количеству плодотворных согласований. Большинство уже поданных дел связаны с утверждением соглашений как в судебном, так и во внесудебном порядке. Пересчет в основном с помощью своих сотрудниковстажеров, которые в большинстве случаев являются посредниками в слушаниях. Важно отметить, что 4-й суд специального гражданского суда Масара́ является судом, который имеет наибольшее количество стажеров более высокого юридического уровня, с учетом их партнерских отношений, подписанных как TJAP, Фекомерсио, FEMICRO и SEBRAE (Serra, 2015).

Таким образом, специальные суды развивались много с момента его создания, через закон 9.099/95, который оказался чрезвычайно важным для реорганизации правосудия, перед лицом больших требований судебных исков. А также валоризации ME и ЕРP, получить место в специальных судах, бороться в более достойным образом за свои права, будучи 4-й суд специального гражданского суда Масара́ (бывший суд микропредприятий и небольшой компании Масара́), пионером в Бразилии.

\section{ЦЕЛЬ}

Проанализировать роль посредника в специальном виртуальном гражданском суде в 4avara специального гражданского суда Macapá AP, Amazônia, Бразилия. 


\section{МЕТОД}

Количественные и качественные исследования с использованием данных 4-го суда Специального гражданского суда города Macapá, Amapá, Амазонки, Бразилия, по вопросу о примирении в судебном разбирательстве.

\section{РЕЗУЛЬТАТЫ И ОБСУЖДЕНИЕ}

Специальные гражданские суды являются органами, которые составляют обычное правосудие, и были созданы с целью примирения, процесса, судебного разбирательства и исполнения, в причинах их юрисдикции, дисциплинированных Федеральным законом № 9099 от 26 сентября 1995 года. В основе этих разбирательств можно привести критерии устности, простоты, неформальности, процедурной экономии и скорости, направленные, по возможности, на возмещение ущерба, причиненного жертве, и применение наказания, не связанного с лишением свободы (Neto e Júnior, 2011).

Реальной целью специальных гражданских судов является решение проблем доступа к правосудию, в основном связанных с расходами и задержкой дел, а также многочисленные препятствия, с которыми сталкиваются граждане, призывающие к правосудию (Guimarães, 2013).

Специальные гражданские судьи все чаще присутствуют в жизни всего населения, поскольку их собственное существование оправдано. Он представлен своим современным способом действия, качеством обслуживания и интересами своих лидеров, что делает их все более гибкими и доступными (Bacellar, 2003).

Специальный гражданский суд обладает юрисдикцией для примирения, судопроизводства и вынесения решений по гражданским делам меньшей сложности, являются примерами: дела, стоимость которых не превышает сорока минимальных размеров заработной платы; те, которые перечислены в ст. 275, пункт II Гражданского кодекса процедуры; действие по выселению для $\mathrm{RC}: 85947$ Ссылка доступа: https://www.nucleodoconhecimento.com.br/закон/специальномгражданском 
собственного использования; владение недвижимостью стоимости, не превышающей сороковую минимальную заработную плату; внесудебные исполнительные ценные бумаги (эмиссионые купюры, чеки, контракты) в размере до сорока минимальных размеров заработной платы; сбор и компенсация ущерба (например, ущерб в результате дорожно-транспортных происшествий) (Barouche, 2010).

\section{ПРИНЦИПЫ СПЕЦИАЛЬНЫХ ГРАЖДАНСКИХ СУДЕЙ}

Создание специальных судей является важной вехой для правового мира во всех его сферах, что обусловив необходимость выделения принципов, лежащих в основе этого порядка, как в поиске его значения, так и в сорере охвата и применимости правовой нормы (Porto, 2008).

По словам Sérpias (2015 г.), «цель создания специального гражданского суда быстро и экономично решать мелкие вопросы гражданина в день». Таким образом, закон был создан на основе принципов, совместимых с облегчением доступа к правосудию тех, кто стремится к нему.

\section{ПРИНЦИП УстНОСТИ}

Благодаря современной фрорме специальных судей, принцип устности выделяется своей легкой применимостью. Этот принцип включен в число генералов гражданского судопроизводства с целью вания процессуальных актов посредством устного сообщения, хотя эти акты могут быть сведены к письменной форме (Silva, 2012).

У специальных придворных этот принцип гораздо более присутствует, и только существенное сводится к сроку. Остальные могут быть выгравированы на магнитной ленте или эквиваленте, в соответствии со статьей 13 , No3, закона № 9099/95 (Brasil, 1995). Это свидетельствует о том, что устность не заменила письменность, оба из которых идут рука об руку, поскольку крайне важно сделать процесс и преобразование их процедурных актов в термин.

$\mathrm{RC}: 85947$

Ссылка доступа: https://www.nucleodoconhecimento.com.br/закон/специальномгражданском 
Применение этого принципа также направлено на то, чтобы процессуальные действия выполнялись в один этап или в приблизительное время. Таким образом, этот принцип непосредственно относится к процедурной скорости, поскольку между процедурными практиками не должно быть очень большого разрыва во времени (Silva, 2012). Таким образом, этот принцип направлен на процедурную простоту в качестве средства содействия прогрессу процесса, кульминацией которого является его скорость.

\section{ПРИНЦИП НЕФОРМАЛЬНОСТИ И ПРОСТОТЫ}

Само название этих принципов уже демонстрирует его намерение, направлено на то, чтобы облегчить процесс и доступ к судебной системе, не держа в себе форму, а скорее к большей гибкости процессуальных актов, подтверждающих их всякий раз, когда они достигают своей цели, согласно (ст. 13 Закона 9.099/95): "Ст. 13 - Процессуальные акты будут действительны всякий раз, когда они выполняются в тех целях, для которых они выполняются, выполняя критерии, указанные в ст. 2 настоящего закона" (Brasil, 1995)

Принцип простоты является не чем иным, как развитием принципа неформальности, что, в свою очередь, является попыткой сделать судебные процедуры более неформальными без этого обострения фрормализма и бюрократии. По словам Боббио, рвение к процедурной бюрократии, а не обеспечение полной эффрективности судебного обеспечения в конечном итоге привело к задержке разбирательства (Porto, 2008).

Практическим примером этих принципов является то, как почтовые цитирования сделаны из юридических лиц частного права, будучи действительным с простой доставкой корреспонденции любому сотруднику, отвечающим за прием (ст. 18, пункт II закона №. 9.099/95), в отличие от Гражданского кодекса, который предусматривает предоставление определенных лиц, например тем, кто имеет управленческие или административные полномочия; (ст. 18, № 2 закона 9,099/95) (Brasil, 1995): "Искусство. 18 - Цитата должна быть с[...]делана: II - в 
случае юридического лица или фризической фрирмы, путем доставки лицу, отвечаю за прием, который должен быть обязательно определен ".

Таким образом, эти два принципа с основной целью привлечения простейшего населения на форум, так как наиболее обездоленных часть людей и мирян в правовых делах чувствует себя застенчивым перед адвокатами, судьями, фрормализмами и людьми с более надуманными словарями.

\section{ПРИНЦИП ПРОЦЕДУРНОЙ ЭКОНОМИКИ}

Другим принципом является процедурная экономика, которая, в свою очередь, является руководством не только специального суда, но и общей теории процесса в целом, поскольку через него имеется как основная цель достижения как можно большего общего результата с наименьшими возможными экономическими расходами (Sérpias, 2015).

Поэтому этот принцип направлен на то, чтобы в кратчайшие сроки и наименее дорогостоящим образом было выполнено наибольшее число процессуальных актов.

\section{ПРИНЦИП ПРОЦЕДУРНОЙ СКОРОСТИ}

Что касается принципа скорости, то это обеспечивает эфффективность правосудия с целью о том, чтобы последствия приговора, например, были практичными и быстрыми, а не медленными темпами, как это происходит во многих случаях, особенно вне специальных судов (Sérpias, 2015)

По словам Sérpias (2015 г.), «задержка в судебном обеспечении стала правилом, когда оно должно быть исключением. Задержка с окончанием процесса была институционализирована». Таким образом, другие принципы являются не более чем переходом к принципу скорости с целью ускорить этот процесс.

Поэтому, без сомнения, наивысшим ожиданием, порожденным Законом 9.099/95, является обещание скорости без нарушения принципа безопасности правовых $\mathrm{RC}: 85947$ Ссылка доступа: https://www.nucleodoconhecimento.com.br/закон/специальном- 
стоков. С целью сделать этот процесс более гибким и быстрым, и только таким образом достичь своей главной цели, эффрективного реагирования судебного обеспечения на общество.

\section{КОМПЬЮТЕРИЗАЦИЯ СПЕЦИАЛЬНЫХ ГРАЖДАНСКИХ СУДЕЙ- PROJURD}

В последние годы мир переживает значительный технологический прогресс, связанный с отсутствием фризического пространства для охраны многочисленных процессов, особенно после конституции 1988 года и интернационализации экономики с созданием реальных факторов, которые используют число судебных исков. После этого бразильская судебная система создала общество PROJUDI (цифровой судебный процесс) (Silva, 2012).

Основная цель создания PROJUDI направлена на ускорение правосудия, сокращение расходов, увеличение потенциала обработки действий, содействие работе юристов и повышение качества обслуживания сторон. Таким образом, это может положить конец тем полкам, которые были заполнены бумагами, поскольку в предыдущие десятилетия эти процессы были сделаны практически ручной работы, что позволило сократить время ожидания для оценки просьб, всегда стремясь к более быстрому урегулированию конфликтов, не причиняя ущерба сторонам.

Настоящая революция началась с закона 11.419/2006, с целью дисциплинирования электронного процесса, с глубокими изменениями в Гражданском кодексе, и с целью рационализации, повышения, сокращения пути, созданного бюрократией и расстоянием, всегда общим в процессах. Мы видим, что два поля значительно развились с компьютеризацией, гибкостью и процедурной скоростью, потому что все процессы передаются через Интернет без необходимости покидать офис (Carvalho, 2006).

Что же связано с компьютеризацией, то в 2005 году государство Amapá пошло дальше, и в 2005 году была создана система TUCUJURIS, технологическое $\mathrm{RC}: 85947$ Ссылка доступа: https://www.nucleodoconhecimento.com.br/закон/специальном- 
устройство, которое стремится управлять и развивать деятельность судебных органов в электронном виде. Компьютеризация судебных процедур и выполнение в Судебных секретариатах, а также хранение содержания различных процессуальных актов, тем самым направленных на повышение гибкости услуг, заменяя нынешнюю нынешнюю систему (Тјар, 2016).

Система TUCUJURIS совершенствуется на протяжении многих лет, и ее процедуры улучшаются все больше и больше, с добавлением новых функций, которые делают его более интегрированным программным обеспечением в рамках правосудия, диверсифицируя его эксплуатацию, стремясь дать большую эфффективность исполнения юрисдикционных актов серверов, магистратов, адвокатов и прокуроров, а также более быстрое реагирование на другие члены общества, которые используют эту услугу (Тјар , 2016).

Поэтому компьютеризация необходима для поддержания быстрой и эфффективной справедливости, поскольку она делает судебную систему современной, следуя современным технологическим тенденциям.

\section{ПРИМИРЕНИЕ В СПЕЦИАЛЬНЫХ СУДЕЙ CIVЕIS}

Институт примирения известен подавляющему большинству бразильцев. Однако его применение в области права, связанное с вопросами, связанными с примирительным правосудием, по-прежнему представляется новым для многих (Guimarães, 2013).

Хотя примирение присутствует в бразильской правовой системе со времен империи, именно в последние десятилетия этот институт получил известность. После политической эмансипации Бразилии в 1822 году конституция империи открыто поощряла урегулирование конфликтов внесудебными средствами, а примирение является упреждающим и необходимым условием для рассмотрения любого дела, при этом фригура правосудия мира является основным средством разрешения судебного разбирательства (Silva, 2013). 
В 1982 году был опубликован закон специальных судов мелких причин с целью дебюрократизации судебной системы на национальном уровне. Будучи создан в 1984 году этот суд окончательно, по закону 7.244/84 (Sérpias, 2015).

C принятием этого закона примирение вновь приобрело видное место в урегулировании конфликтов, включая включение фригуры посредника, которая будет изучена позже (Guimarães, 2013).

Примирение является методом, используемым в менее сложных конфрликтах, при котором третий посредник может занять более активную, но нейтральную позицию в отношении конфликта, не теряя беспристрастности. Это краткий консенсусный процесс, который направлен на эфффективное урегулирование конфликтов в возможных пределах социальных отношений между вовлеченными сторонами (Sérpias, 2015).

Таким образом, "примирение является институтом процесса, поскольку оно является одним из его моментов, который приводит к процедурным последствиям, привилегии любознательному принципу и роли промежуточного судьи в фрормировании воли сторон" (Nassif, 2005).

Примирение является самостоятельным процессом, в ходе которого беспристрастная третья сторона (посредник) оказывает помощь сторонам в конфликте, с тем чтобы найти удовлетворительное решение для всех сторон (Silva, 2013).

Примирение в 4-м суде гражданского суда, является достаточно развитым и практикуется, будучи таким судом на национальном уровне известен своей работой разработаны и ряд положительных примирений. Большинство уже поданных дел являются плодом одобрения соглашений, как в судебном, так и во внесудебном порядке (Serra, 2015).

Тогда можно сделать вывод о том, что институт примирения, несомненно, является наиболее широко используемым и хорошо известным альтернативным 
средством урегулирования конфликтов в Бразилии, позволяющим правосудию быстро урегулировать свои требования, а также делает реальной возможность мирного урегулирования проблем.

\section{ШАГИ ПО ПРИМИРЕНИЮ}

Примирение, каким бы неофициальным он ни был, имеет некоторые шаги, которые должен соблюдаться посредником при строительстве соглашения, что не является нормами. Однако соблюдение этих мер помогает в скорости и эфффективности процесса (Sérpias, 2015).

Поэтому примирение имеет руководящие принципы, которые следует соблюдать, и не должно происходить по простой воли сторон или посредника. Ниже мы упомянем основные этапы примирения.

\section{ПРИМИРИТЕЛЬНЫЕ И ЕГО ХАРАКТЕРИСТИКИ В ВИРТУАЛЬНОМ ГРАЖДАНСКОМ СУДЕ}

Интересным вопросом на данный момент является фригура посредника в процедурах закона 9.099/95. Посредники предпочтительно будут набраны из студентов юридических лиц. Так что, если закон сказал предпочтительно, это не делает его обязательством. Таким образом, ученые-правоведы могут также фригуры в качестве посредников. В соответствии с Законом 9.099/95: "Ст. 7. Посредники и непрофессиональные судьи являются помощниками правосудия, набраны, во-первых, предпочтительно, среди студентов юридических работников, а во-вторых, среди юристов с более чем пятилетним опытом работы" (Brasil, 1995).

На практике подавляющее большинство примирителей Специального гражданского суда являются студентами юридических вузов, которые обычно поступают в университеты после поступления в пятый семестр. Быть партнером, где вы обмениваеесь работой на опыт, не будучи другим в 4-м суде специального гражданского суда (Serra, 2015).

RC: 85947

Ссылка доступа: https://www.nucleodoconhecimento.com.br/закон/специальномгражданском 
Посредник является одним из субъектов примирения и должен действовать нейтрально и беспристрастно, создавая момент и ситуацию, стороны которых могут чувствовать себя комфортно в переговорах. Он должен использовать свою психологию, чтобы сделать примирение плодотворным, через воли сторон на противоположных сторонах, то есть посредник является не более чем посредником (Porto, 2008).

Даже неся все эмоциональное бремя, во время согласительного слушания посредник должен быть максимально беспристрастным и нейтральным, должен обеспечить плавность и легитимность процесса (Silva, 2013). Беспристрастность посредника имеет основополагающее значение для примирения, это означает, что он не будет привилегии любой из сторон, а тем более вопрос значение суждения, связанные с конфликтом. Таким образом, она должна передать доверие сторонам. Только таким образом можно построить справедливое соглашение для всех (Amaral, 2011).

Что касается 4-го суда специального гражданского суда, будучи очень известным по количеству плодотворных примирений, полученных в ежедневных слушаниях или мероприятиях, проводимых спорадически, как: государственная или национальная неделя примирения и "суббота также примирительный день", выделяется эфффективностью своих посредников, и большинство из них являются стажерами более высокого уровня права, учитывая их партнерские отношения, подписанные между судом и TJAP, Фекомерсио, FEMICRO и SEBRAE (Serra, 2015).

Таким образом, фригура посредника перед лицом примирения имеет основополагающее значение, поскольку именно он организует и проводит работу. Он должен действовать в соответствии с законом и руководящими принципами, которые должны соблюдаться. 


\section{ЭФФЕКТИВНОСТЬ ПРИМИРЕНИЯ}

Отсутствие эффрективности и ускорения не только является основными проблемами правосудия, но и другие ситуации помогают отсрочить и остановить судебную систему. Поэтому в соответствии с Федеральной конституцией 19888 года и регулируемой законом 9 099/95 специальные гражданские суды стали способом расширения доступа к правосудию и были охарактеризованы как "клапан побега" для общего правосудия, изменив традиционные процедуры, которые были неэффрективными, особенно для урегулирования мелких конфликтов (Guimarães, 2013).

Создание специальных судов и использование согласительной процедуры имеют эффрективность, выходят далеко за рамки того, что ожидается, поскольку помимо разгневания судебной системы оно привело к тому, что граждане, которые до этого не использовали эти средства для урегулирования своих конфрликтов, тем самым распространяя закон и культуру мира (Guimarães, 2013).

Таким образом, на протяжении многих лет примирение оказывается эфрфективным, поскольку оно не связано с судебной системой, путем сокращения расходов, сроков и урегулирования причин менее сложных ситуаций, создавая новые параметры урегулирования конфликтов в правосудии в целом с учетом скорости (Guimarães, 2013).

Таким образом, большая скорость работы специальных судей основывается на идее скорости и эффрективности, и существует два способа повышения эфффективности, качественная и количественная. Количественный не касается процессуального качества, учитывая только скорость процедур и сокращение расходов, а качественный, наоборот, касается содержания решений, учитывая их качество в отношении соблюдения и принятия демократического процесса со всеми присущими ему нормами (Neto, 2015).

В этом смысле можно сказать, что, хотя специальные суды и согласительные процедуры эфффективны, быстрое их разбирательство не означает, что RC: 85947 Ссылка доступа: https://www.nucleodoconhecimento.com.br/закон/специальномгражданском 
проблемы судебной системы решены, а тем более можно сказать, что правосудие в целом является быстрым (Barouche, 2010).

Что касается Масара́, то специальные судьи являются весьма эфффективными, учитывая стимулы к примирению (Serra, 2015).

Например, 4-й суд специального суда Масара́, бывший суд микропредприятий и малого бизнеса, проводит весьма конкретную и эффрективную работу с использованием согласительной процедуры, будучи национально признанным за свою работу, которая ежегодно приводит к плодотворным примирениям (Serra, 2015).

В течение года проводятся многочисленные согласительные действия, такие, как, например, государственные и национальные согласительные недели. В них 4-й суд специального гражданского суда Макапе всегда является тем, кто делает наиболее плодотворные примирения (Serra, 2015).

Физическая часть суда, несомненно, значительно ограничивает число согласительных процедур, но несмотря на это, ежедневно проводится от 12 до 25 согласительных слушаний, что является более высоким числом по сравнению с другими специальными судами центрального суда Macapá (Serra, 2015). 
Рисунок 1-показывает количество дел, касающихся примирения, инструктата и вынесения решений

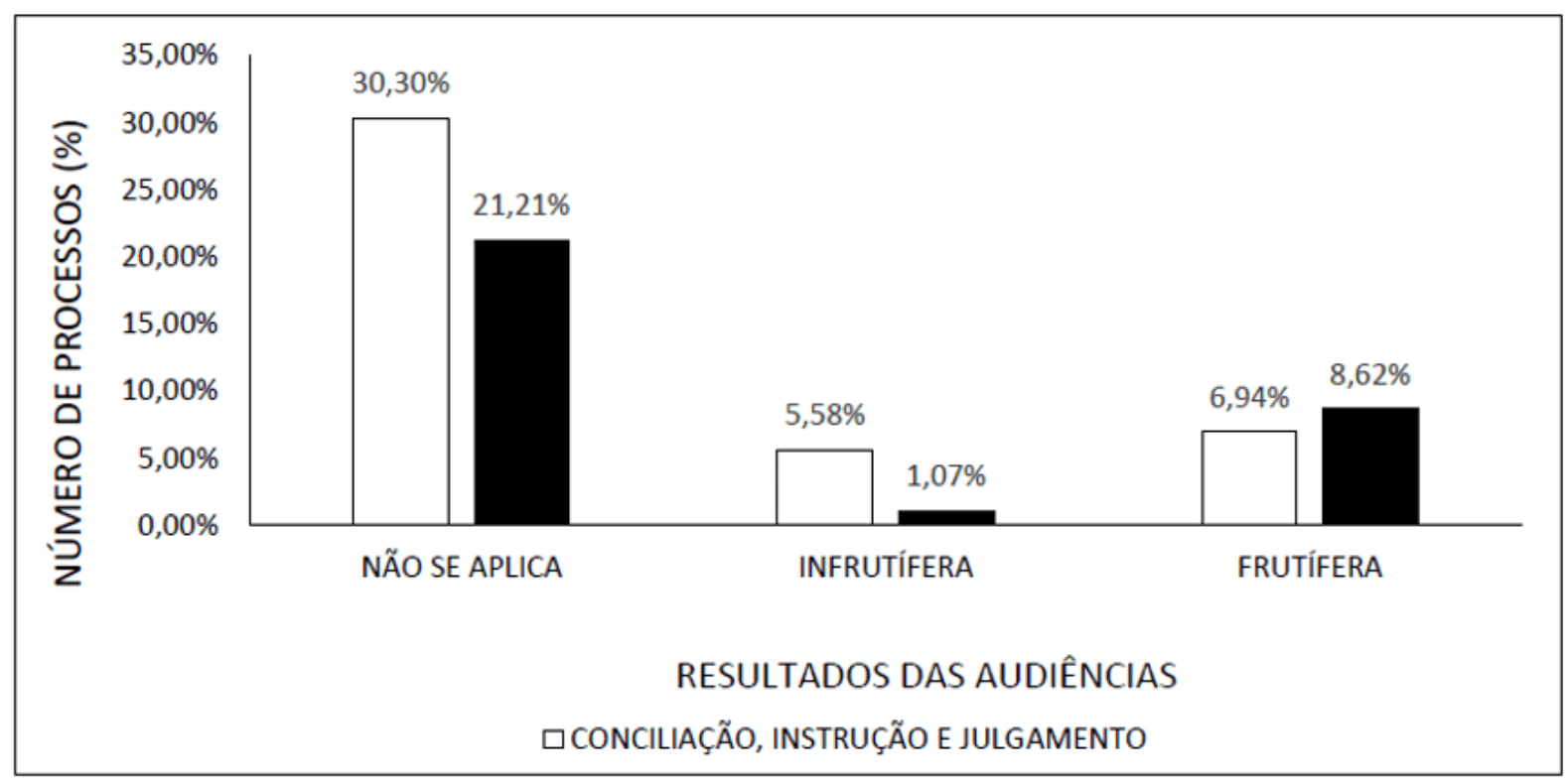

(Ceppa, 2015).

На рисунке 1 показана эффрективность согласительных слушаний, проводимых в 4-м суде специального гражданского суда Масара́. В ходе первых согласительных слушаний процент плодотворных соглашений выше; и неудачное соглашение меньше (с учетом присутствия посредника) по отношению к этапу обучения и суждения, перед судьей.

Поэтому можно сделать вывод о том, что цель создания специальных судов была достигнута в 4-м суде специального гражданского суда Масара́, поскольку на основе примирения число требований, высовывахаемых на основе соглашений, имеет важное значение по сравнению с другими процессуальными этапами. Таким образом, показывая эффрективность посредника в качестве драйвера согласительных слушаний.

\section{ВЫводы}

Ввиду увеличения числа дел судебная система, как представляется, стала перегруженной и неэффрективной, и необходимо изыскивать новые средства RC: 85947 Ссылка доступа: https://www.nucleodoconhecimento.com.br/закон/специальномгражданском 
урегулирования конфликтов. Ответом судебных органов стало создание специальных судов с использованием согласительной процедуры.

Произошла историческая эволюция специальных судей, от их осуществления до принятия закона 9.099/95 до разработки таких принципов, как процедурная скорость, неформальность и, все это указывает на осуществление более быстрого и эфффективного процесса.

PROJUD и TUCUJURIS путем компьютеризации специальных судов, как представляется, имеют важное значение в модернизации процесса, делая их проще, быстрее и доступнее для всех и, таким образом, после глобальных технологических тенденций

Институт примирения оказывается основным альтернативным средством урегулирования конфрликтов, фоормой самоопределения, с помощью которого стороны создают решение проблем, быстро разгоняя судебную систему.

Примирение на основе скорости, низких затрат и эфффективности, как представляется, делает судебную систему более привлекательной для части общества с низким уровнем дохода и для миряных в этом вопросе, которые верят в возможность решения своих проблем за счет правосудия, создавая тем самым позитивные последствия для социального умиротворения.

Эволюция специального разбирательства, основанного на согласительной процедуре, не была бы эффрективной без присутствия посредника. Именно он направляет стороны к разработке соглашения, проводя беспристрастно, направляя процедуру на основе многочисленных принципов и руководящих принципов. Таким образом, следует более обеспокоены формированием этих агентов, поскольку именно они находятся на переднем крае большинства требований судебных органов, непосредственно и ежедневно сталкиваются с населением и его проблемами в стрессовых ситуациях, а иногда и трудно примириться. 
Специальные суды в целом должны стремиться все больше и больше инвестировать в посредников и действия, направленные на примирение, такие, как государственные и национальные недели примирения, поскольку, таким образом, существует большая вероятность того, что дела в судебной системе приобретут большую беглость.

\section{ссылки}

AMARAL, R. L. S. D. A Concilição no Processo Judicial, . 2011. 64 (Graduação). Faculdade de Ciências Jurídicas da Universidade Tuiuti do Paraná, Curitiba PR.

BACELLAR, R. P. Juizados Especiais - a Nova Mediação Paraprocessual. São Paulo: Revista dos Tribunais, 2003. 286.

BAROUCHE, T. D. O. Os Juizados Especiais Cíveis e a Problemática da Celeridade Processual. Revista de Direito dos Monitores da UFF, n. 7, p. 1-24, 2010.

BRASIL. LEI № 9.099, DE 26 DE SETEMBRO DE 1995. JURÍDICOS, S. P. A. Brasília DF: Presidência da República - Casa Civil 1995.

CARVALHO, J. P. C. D. A Era Virtual do Processo Judicial: A Experiência dos Juizados Especiais Virtuais e o Projeto de Lei de Informatização do Processo. Revista Direito e Liberdade, v. 3, n. 2, p. 453 - 484, 2006.

GUIMARÃES, A. A Crise do Judiciário e a Eficácia da Conciliação nos Juizados Especiais Cíveis Estaduias de São Luis - MA. Revista Thesis Juris, v. 2, n. 1, p. 142$161,2013$.

NASSIF, E. Conciliação judicial e indisponibilidade de direitos: paradoxos da “justiça menor" no processo civil e trabalhista. São Paulo SP: Editora LTR, 2005.

NETO, A. G. A Audiência de Conciliação no Novo Código de Processo Civil. Revista Eletrônica de Direito Processual - REDP. 16, n. 16, p. 29-57, 2015. 
NETO, F. D. C. T.; JÚNIOR, J. D. F. Juizados Especiais Estaduais Cíveis e Criminais. Comentários à Lei no 9.099/95. 7ª̣ed. São Paulo: Revista dos Tribunais, 2011. 960p.

PORTO, A. P. G. Juizados Especiais Cíveis - O Papel do Conciliador 2008. 59p. (Especialização). Universidade Estadual Vale do Acaraú, Fortaleza CE.

SALOMÃO, L. F. As Microempresas nos Juizados Especiais. Revista da EMERJ, v. 4, n. 4, p. 62-73, 2001.

SENA, A. G.; RICHA, M. D. A. A conciliação judicial trabalhista em uma política pública de tratamento adequado e efetivo de conflito de interesses. In: PELUSO, A. C. e RICHA, M. D. A. (Ed.). Conciliação e mediação: estruturação da política judiciária nacional. Rio de janeiro RJ: Forense, 2011. p.115-139.

SÉRPIAS, L. Juizado Especial, Cível, Criminal, Federal e da Fazenda Pública. São Paulo: TradeBook, 2015. 1615p.

SERRA, A. B. C. S. Juizado Especial da Microempresa e Empresa de Pequeno Porte: Um Estudo de Caso na Cidade de Macapá. 2015. 18p. (Graduação). Estácio de Sá, Macapá AP.

SILVA, É. B. Conciliação Judicial. Brasília DF: Gazeta Juridica, 2013. 432p.

SILVA, P. G. A Conciliação como Instrumento de Solução de Conflitos. 2012. (Graduação). Centro Universitário Eurípides de Marília - UNIVEM, Marília SP.

TJAP. Sistema TUCUJURIS - Processo Judicial Eletrônico. Macapá AP, 2016. Disponível em: < http://www.tjap.jus.br/portal/sobre.html >. Acesso em: 22/02/2016.

TOLENTINO, A. V. A competência do Juizado Especial Cível. 2011. Disponível em: < http://www.direitonet.com.br/artigos/exibir/6387/A-competencia-do-JuizadoEspecial-Civel >. Acesso em: 30/05/2016. 
Представлено: Май, 2021.

Утверждено: Май, 2021. 